\title{
AÇÕES DE ENFERMAGEM NO CENÁRIO DO COTIDIANO DE UMA INSTITUIÇÃO PSIQUIÁTRICA
}

Maria Conceição Bernardo de Mello e Souza ${ }^{1}$

Souza MCBM. Ações de enfermagem no cenário do cotidiano de uma instituição psiquiátrica. Rev Latino-am Enfermagem 2003 setembro-outubro;11(5):678-84.

Estudo qualitativo com proposta de observar e descrever as ações de enfermagem que os enfermeiros desenvolvem em uma instituição psiquiátrica estatal. Participaram deste trabalho oito enfermeiros contratados pela instituição. Para coleta de dados foi utilizada a observação participante e registro em diário de campo. As discussões dos resultados foram alicerçadas em autores que trabalharam com a prática de enfermagem em instituições psiquiátricas. Os dados evidenciaram que as ações de enfermagem eram predominantemente de natureza burocrática e administrativa e que os profissionais investigados não tinham posição definida sobre a necessidade de realizar intervenção na assistência de enfermagem desenvolvida no local.

DESCRITORES: enfermagem psiquiátrica; hospitais psiquiátricos; saúde mental

\section{NURSING ACTIONS IN THE DAILY SCENARIO OF A PSYCHIATRIC INSTITUTION}

This qualitative study had the purpose to observe and describe nursing actions performed by nurses at a state psychiatric institution. Eight nurses who work in the institution participated in the study. In order to collect data, authors used participant observation and registration in a field record book. The discussions regarding the results were based on research about nursing practice in psychiatric institutions. Data evidenced that nursing actions were predominantly bureaucratic and administrative and that the professionals studied did not have a defined position about the need to perform interventions in the nursing care provided in this institution.

DESCRIPTORS: psychiatric nursing; psychiatric hospitals; mental health

\section{ACCIONES DE ENFERMERÍA EN EL ESCENARIO DEL COTIDIANO DE UNA INSTITUCIÓN PSIQUIÁTRICA}

Estudio cualitativo con propuesta de observar y describir las acciones de enfermería que los enfermeros desarrollan en una institución psiquiátrica estatal. Participaron en este trabajo 8 enfermeros contratados por la institución. Para la recolección de datos se utilizó la observación participante y el registro en diario de campo. Las discusiones de los resultados fueron basadas en autores que trabajan con la práctica de enfermería en instituciones psiquiátricas. Los datos evidenciaron que las acciones de enfermería eran predominantemente de naturaleza burocrática y administrativa y que los profesionales investigados no tenían una posición definida con respecto a la necesidad de realizarse una intervención en la atención de enfermería desarrollada en el local.

DESCRIPTORES: enfermería psiquiátrica; hospitales psiquiátricos; salud mental

\footnotetext{
${ }^{1}$ Professor Doutor da Escola de Enfermagem de Ribeirão Preto, da Universidade de São Paulo, Centro Colaborador da OMS para o desenvolvimento da pesquisa em enfermagem, e-mail: consouza@eerp.usp.br
} 
INTRODUÇÃO

No decorrer de minha trajetória profissional venho me aproximando do trabalho desenvolvido pelos enfermeiros assistenciais nas instituições de atendimento psiquiátrico da cidade de Ribeirão Preto.

Iniciei as atividades como enfermeira de serviço trabalhando em hospitais psiquiátricos. Durante um ano atuei em uma clínica psiquiátrica particular, conveniada com o antigo Instituto Nacional de Previdência Social (INPS) e, por outros quase quatro anos, em um macrohospital estadual. Em 1985, fiz um Curso de Especialização em Enfermagem Psiquiátrica e, em 1989, ingressei na carreira universitária, tendo como área de atuação a Enfermagem Psiquiátrica. No ano de 1991, entrei no Curso de Pós-Graduação, Nível Mestrado, Área Enfermagem Psiquiátrica e, em 1996, no Doutorado em Enfermagem. Nesse período, mantive o vínculo com os enfermeiros assistenciais, através de assessoria a grupos de profissionais e também da proximidade com os alunos do Curso de Especialização em Enfermagem Psiquiátrica e Saúde Mental que, em geral, são enfermeiros de instituições que prestam assistência psiquiátrica.

No mestrado, realizei estudo bibliográfico das produções da enfermagem psiquiátrica no Brasil, no período de 1932 a 1993. Esse levou-me a ter uma visão das publicações dos enfermeiros da área, as quais mostraram a trajetória percorrida pela especialidade que, sem dúvida, sofreu influências das práticas de saúde mental vigentes no país, nos períodos estudados, e também da ênfase na pesquisa após o advento da pós-graduação stricto-sensu. A assistência de enfermagem foi a maior preocupação dos pesquisadores durante os 60 anos estudados, sendo que dos 361 trabalhos publicados, 130 (60\%) abordavam essa temática. O levantamento também apontou que os enfermeiros docentes eram os principais responsáveis pela produção de artigos e os assistenciais escreviam pouco sobre suas experiências ${ }^{(1)}$.

Ainda preocupada com questões relacionadas à formação do enfermeiro, sua prática e o conhecimento considerado específico da área por esses profissionais é que, no doutorado, desenvolvi investigação onde busquei caracterizar os enfermeiros que trabalhavam em instituições psiquiátricas na cidade de Ribeirão Preto, focalizar sua formação, identificar as ações de enfermagem que esses profissionais referiram desenvolver rotineiramente e relacionar formação, prática e conhecimento considerado específico da área pelos mesmos.

Os resultados obtidos mostraram uma população predominantemente feminina em fase adulta, com tempo razoável de serviço na área. Indicaram também que, depois de concluído o Curso de Graduação em Enfermagem, a maioria dos sujeitos estudados não procurou por cursos de especialização, atualização, e não participou de treinamentos e eventos informativos. Entre as ações que os enfermeiros revelaram realizar rotineiramente destacaram-se aquelas de natureza burocráticoadministrativas, apesar de apontarem para as ações de assistência direta, grupais e pedagógicas. Os profissionais consideraram alguns temas como conhecimento específico da enfermagem psiquiátrica e, entre eles, o mais enfatizado foi o relacionamento terapêutico. Além disso, apontaram que adquirem conhecimento sobre a área no ambiente de trabalho, isso é, no seu cotidiano ${ }^{(2)}$.

Paralelamente a essas pesquisas desenvolvi, junto ao Grupo de Estudos de Enfermagem Psiquiátrica e Saúde Mental, do Departamento de Enfermagem Psiquiátrica e Ciências Humanas da Escola de Enfermagem de Ribeirão Preto da Universidade de São Paulo, estudo sobre o ensino de enfermagem psiquiátrica no Brasil, onde fizemos um levantamento nas escolas das várias regiões do país, sobre as disciplinas da área Enfermagem Psiquiátrica e Saúde Mental (conteúdo abordado, estratégias didáticas, bibliografias utilizadas, tipos de campos onde são realizadas aulas práticas e docentes responsáveis). Esse trabalho envolveu pesquisadores das regiões Norte, Nordeste, Centro-Oeste, Sul e Sudeste e, certamente, contribuirá para subsidiar discussões sobre o que está sendo abordado nas universidades e qual a formação do enfermeiro na área ${ }^{(3)}$.

As pesquisas anteriormente descritas, acrescidas de leituras sobre a especialidade, de minha experiência como enfermeira assistencial e atualmente docente da área, levaram-me a questionar: como ocorre a participação do enfermeiro no cenário do cotidiano das instituições psiquiátricas? Qual a colaboração dessa participação no tratamento do(s) indivíduo(s) em sofrimento mental? Quais atividades estão sendo desenvolvidas no local de trabalho?

Como já apontado, os enfermeiros assistenciais das instituições psiquiátricas de Ribeirão Preto, quando abordados a respeito da atuação de enfermagem e do conhecimento obtido sobre enfermagem psiquiátrica e psiquiatria revelaram, entre outras coisas, que suas atividades são essencialmente burocrático-administrativas 
e que adquirem conhecimento sobre a área no próprio ambiente de trabalho, isso é, no seu dia-a-dia ${ }^{(2)}$.

O propósito desta investigação é observar e descrever as ações de enfermagem que os enfermeiros desenvolvem em uma instituição psiquiátrica, contando com a participação dos profissionais envolvidos para, posteriormente, juntos, discutirmos e elaborarmos estratégias de intervenção necessárias à assistência de enfermagem na instituição.

Para desenvolver o presente estudo, fiz um recorte da população pesquisada no trabalho de doutorado, focalizando especificamente os enfermeiros de um hospital psiquiátrico estatal da cidade de Ribeirão Preto, SP. A opção por essa instituição se deve ao fato de que mantenha maior proximidade com o local, por ter sido enfermeira assistencial na mesma durante quase quatro anos, e também por aquela ser a mais antiga instituição psiquiátrica da cidade e atualmente estar passando por processo de transformação, com proposta de desinstitucionalização*.

A seguir passo a uma breve descrição do local onde foi realizada a investigação.

\section{CARACTERIZAÇÃO DO LOCAL DO ESTUDO}

O Hospital, campo da presente investigação, é a mais antiga instituição psiquiátrica da cidade. Foi criado, como as outras instituições psiquiátricas do interior do Estado, na década de 40, para aliviar a superlotação do então Hospital do Juquery, hospício inaugurado em 1898, por Franco da Rocha, e que, rapidamente, expandiu sua população.

Em 1944, o referido Hospital começou a funcionar com a vinda de 20 pacientes do Juquery e, no final do ano de sua inauguração, o mesmo, já contava com 500 internos, todos do sexo masculino. No ano seguinte, foi instalado o primeiro pavilhão feminino, abrigando as mulheres transferidas da unidade de internações que funcionava na cidade, tornando-se, assim, hospital de referência regional ${ }^{(5)}$.

Até 1988, o Hospital possuía extensa área verde, composta por árvores antigas e frondosas, muitos jardins e pomares, com seus limites demarcados por cercas de arame e somente uma entrada principal, onde estavam instalados a guarita e o portão de acesso ${ }^{(6)}$.

Atualmente esse quadro já está modificado, pois a cidade se expandiu e acabou invadindo as fronteiras do hospital. Em uma parte de sua área foi construído um condomínio de edifícios residenciais. A Instituição está localizada em bairro valorizado, na zona sul do município.

O Hospital possui 80 leitos para internação de pacientes agudos ( 40 masculinos e 40 femininos), 20 para dependentes químicos e 223 para crônicos que são considerados moradores.

Os leitos destinados aos pacientes crônicos estão assim distribuídos: 66 para o setor de moradores do sexo feminino, sendo 44 da Unidade de Psiquiatria Feminina e os outros 22 da Unidade de Geriatria Feminina; 128 leitos para o setor de moradores do sexo masculino, sendo 22 destinados aos portadores de deficiências físicas múltiplas, dependentes total ou parcialmente da enfermagem, 28 leitos para Unidade de Geriatria Masculina; 52 para a Enfermaria 7 e 26 para República, unidade de reabilitação, ou seja, de reeducação das atividades da vida diária do paciente e de estímulo às relações interpessoais. O Núcleo de Convívio I, implantado em 1983 como primeira moradia dentro do espaço hospitalar, abriga hoje cinco moradores do sexo feminino e nove do masculino, e o Núcleo de Convívio II, considerado como mais uma casa da Vila Terapêutica, apesar de estar distante das outras cinco casas que foram construídas nos mesmos moldes e com a mesma finalidade, iniciou suas atividades em 1995 e abriga quatro moradores do sexo masculino**.

A Instituição conta também com uma Vila Terapêutica, inaugurada em 1987, constituída por cinco casas padronizadas, com cinco vagas cada uma e que, atualmente, abrigam 14 moradores. Essas casas, construídas dentro do espaço hospitalar, têm como proposta a reinserção social de pacientes-moradores com condições de desenvolverem atividades fora das enfermarias. O Hospital também possui a Clínica Médica, com 15 leitos disponíveis para internação de pacientes com problemas clínicos, advindos de qualquer uma das unidades de internação.

Além disso, o Hospital, desde 1984, com o apoio da Secretaria de Saúde do Estado, realizou as primeiras tentativas de desospitalização com o projeto das Pensões

\footnotetext{
* Entende-se desinstitucionalização não apenas como processo de desospitalização, mas de invenção de práticas assistências territoriais; um processo prático de desconstrução dos conceitos e das práticas psiquiátricas ${ }^{(4)}$

** Esses dados foram obtidos no Serviço de Arquivo Médico (SAME) do Hospital no dia 24/6/2000
} 
Protegidas, que se concretizou em 1992.

Implantaram-se pensões destinadas aos egressos do Hospital, as quais se localizam em bairros da cidade, sendo geridas por sociedades civis filantrópicas, contratadas pelo Estado, que é responsável pela locação dos imóveis. Atualmente existem três pensões: duas femininas e outra onde reside um casal e mais um morador do sexo masculino.

Há uma proposta da Instituição de fundar convênio com a Companhia Habitacional de Ribeirão Preto (COHAB), para ampliação desse projeto de moradia, onde o próprio paciente possa comprar sua casa com o benefício da aposentadoria. Hoje já existem três casas da $\mathrm{COHAB}$ compradas por aqueles que apresentaram condições financeiras. Em julho de 1999, a idéia das casas populares que consta da proposta, foi aprovada na Câmara Municipal, por unanimidade, devendo cada conjunto habitacional reservar um número de casas para os ex-pacientes, já que eles não têm condições de disputar os imóveis em nível de igualdade com os demais concorrentes.

Em 1971, pela primeira vez, o quadro de funcionários do hospital foi ampliado com a contratação de psicólogo, enfermeira e assistente social. Nos últimos 20 anos, já passaram pela instituição cerca de 35 enfermeiros, sendo que mais da metade foi contratada a partir de $1986^{(7)}$.

A equipe de saúde é composta por 29 médicos (21 psiquiatras, 10 clínicos gerais, um radiologista, um Diretor Técnico de Departamento de Saúde, um Diretor Técnico de Divisão de Saúde e um Assistente Técnico de Saúde III); 18 enfermeiros (três desses Diretores Técnicos de Divisão de Saúde e um Diretor Técnico de Serviço de Saúde); seis terapeutas ocupacionais (um Diretor Técnico de Divisão da Saúde); nove psicólogos (um Diretor Técnico de Divisão da Saúde); 10 assistentes sociais (um Diretor Técnico de Divisão de Saúde e um Diretor Técnico de Divisão); dois dentistas; quatro farmacêuticos; dois técnicos de laboratório; dois técnicos de radiologia; 145 auxiliares de enfermagem; dois auxiliares de laboratório; 13 auxiliares de serviços da saúde*.

No momento em que esta pesquisa estava sendo realizada ocorreu alteração na denominação do Hospital e modificação em sua estrutura administrativa, que passou a ser regido por gerências. Além disso, uma das finalidades da Instituição é participar do processo de transformação da assistência psiquiátrica que consiste na implementação do modelo assistencial humanizado, no rompimento da lógica manicomial e na desinstitucionalização ${ }^{(8)}$.

\section{PROCEDIMENTOS METODOLÓGICOS}

Este é um estudo de natureza qualitativa e que teve como objetivo observar e descrever as ações de enfermagem desenvolvidas pelos enfermeiros assistenciais em um hospital psiquiátrico estatal.

O grupo de enfermeiros participantes deste trabalho foi composto por 12 profissionais contratados pelo Hospital e que fizeram parte da população investigada na tese de doutorado já mencionada. Dos 12 enfermeiros inicialmente contatados, quatro não participaram da pesquisa, pois, no momento da coleta de dados, dois deles estavam impossibilitados de acompanhar as atividades rotineiras, por motivos variados, como: participação em reuniões de gerenciamento, administrativas, férias, entre outros; e dois pediram demissão antes do início da coleta de dados.

O contato com os mesmos foi realizado após análise do projeto pelo Comitê de Ética da Escola de Enfermagem de Ribeirão Preto, da Universidade de São Paulo, e a análise e autorização da Comissão de Ética Médica e Direção do Hospital para a pesquisa ser realizada.

Em um primeiro momento, agendei reunião com o grupo de enfermeiros onde apresentei os resultados obtidos na tese de doutorado, da qual fizeram parte da população investigada, e fiz a proposta de dar continuidade ao estudo anterior, agora visando observar suas atividades diárias. O projeto foi aceito pelo grupo que se mostrou disposto a colaborar nesta pesquisa.

Ainda esclareci que seria preservado o anonimato dos mesmos, e que, após as observações realizadas e registradas, agendaria outras reuniões para que pudéssemos trabalhar as informações obtidas e definirmos propostas de intervenção na assistência de enfermagem, se assim concluíssemos necessário.

Os enfermeiros solicitaram um tempo para se organizarem, pois se iniciava no Hospital um processo de mudanças na estrutura administrativa (gerenciamento) e ainda estava tudo muito tumultuado.

\footnotetext{
* Dados obtidos no Setor de Recursos Humanos do Hospital em 13/9/2000. Diretor Técnico de Divisão de Saúde e Diretor Técnico de Serviço de Saúde, níveis hierárquicos, conforme Decreto o 44786 , de 23/3/2000 ${ }^{(8)}$
} 
Os dados foram coletados no período de julho de 2000 a março de 2001, considerando as dificuldades de horário, escala e férias dos sujeitos.

Para coleta de dados optei pela observação participante e registro do desenvolvimento das atividades diárias dos sujeitos em diário de campo.

A observação participante deve tender a ser a mais profunda possível, através da observação informal, da vivência de acontecimentos julgados importantes pelos observados e do acompanhamento das rotinas cotidianas. Trata-se de observação em curto espaço de tempo e suas limitações advêm de contato bastante superficial ${ }^{(9)}$.

O observador participante deve apresentar-se ao grupo a ser pesquisado e esclarecer os objetivos do estudo desde o início. Deverá aceitar o controle do grupo sobre o que será, ou não, tornado público pela pesquisa ${ }^{(10)}$.

Inicialmente agendei com cada profissional os dias para acompanhá-lo durante o desempenho de suas atividades rotineiras, coletando as informações através da observação participante (participava junto de todas as atividades por ele desenvolvidas) e depois realizava o registro em diário de campo. Observei cada enfermeiro por dois dias, no período de plantão de 6 horas/dia.

Para análise dos dados foi preciso ler e reler 0 material registrado no diário de campo, onde procurei relatar passo a passo as atividades cotidianas dos profissionais investigados. Quando já esgotada a leitura, passei à realização da classificação dos dados de acordo com categorias teóricas que emergiram espontaneamente.

A categorização, por si mesma, não esgota a análise. Sendo assim, busquei ajuda na literatura existente sobre o tema estudado para subsidiar a discussão.

Em junho de 2001, com os dados já organizados, solicitei reunião com os enfermeiros, na qual mostrei os resultados obtidos das observações, para que discutíssemos em grupo a necessidade de uma intervenção na assistência de enfermagem naquela Instituição para, posteriormente, elaborarmos estratégias para efetivá-la.

\section{RESULTADOS E DISCUSSÃO}

As ações de enfermagem desempenhadas pelos enfermeiros, no cotidiano da instituição, foram agrupadas em categorias, após a leituras e releituras sucessivas do material coletado e registrado em diário de campo.
As categorias que emergiram foram as seguintes: ações centradas no cuidado dispensado ao paciente/ morador que incluem os cuidados e orientações sobre higiene pessoal, atividades que promovem segurança e conforto, assim como aquelas referentes ao trabalho educativo, realizado com a clientela; ações complementares aos cuidados de enfermagem, que abrangem orientação do auxiliar de enfermagem sobre técnicas e condutas, conferência de medicações, auxílio ao médico psiquiatra durante a consulta e troca de informações sobre o comportamento do paciente, discussão sobre medicações prescritas, anotações de enfermagem e passagem de plantão; ações administrativas e burocráticas que compreendem todas aquelas referentes ao planejamento, gestão, coordenação, supervisão e avaliação da assistência de enfermagem e aquelas que podem ser delegadas e efetuadas por outros, que não necessariamente o enfermeiro.

A seguir, descreverei as ações de enfermagem observadas e registradas no período da coleta.

Ações centradas no cuidado dispensado ao paciente/morador- Alguns enfermeiros administram cuidados básicos, como, por exemplo, acompanham e orientam no café da manhã, outros realizam curativos. Um dos sujeitos observados orienta o morador no banho de aspersão e arrumação de cama; outro orienta na escovação de dentes e outro ainda realiza mudança de decúbito em paciente acamado com úlcera de pressão.

Percebi que, de maneira geral, essas ações são realizadas mecanicamente, não havendo um planejamento dos profissionais. As atividades são delegadas aos auxiliares de enfermagem que desenvolvem os cuidados como banho, troca de roupas, alimentação, curativos, medicações, entre outras, sem a supervisão do enfermeiro.

Notei que a relação enfermeiro/paciente, que é teoricamente valorizada durante os cursos de graduação em enfermagem, na prática deixa a desejar, pois o enfermeiro parece não ter "tempo" para sentar e escutar o paciente.

Um estudo realizado anteriormente mostrou que $46,7 \%$ dos enfermeiros de instituições psiquiátricas da cidade de Ribeirão Preto, SP consideraram o relacionamento terapêutico como conhecimento específico da enfermagem psiquiátrica ${ }^{(2)}$.

Essa parece ser uma contradição existente entre a fala e a ação do enfermeiro.

Desde o final da década de 60, o relacionamento 
terapêutico com pacientes, familiares e equipe passou a ser o enfoque do ensino de enfermagem psiquiátrica ${ }^{(11)}$.

Outros estudiosos que investigaram sobre o ensino da enfermagem psiquiátrica no Brasil confirmaram a importância dada ao processo interpessoal ${ }^{(12-15)}$.

Ações complementares aos cuidados de enfermagem- Dos profissionais investigados, alguns realizam leitura de prontuários e livros de ocorrências que contêm informações gerais sobre os pacientes; conversam com o médico psiquiatra sobre o comportamento e conduta em relação aos pacientes recém-internados; visitam os mesmos no leito ou pátio; realizam agendamento de retorno dos doentes em consultas fora do hospital e solicitam informações sobre o cliente que foi encaminhado para internação em hospital de clínica geral; um confere medicações psicotrópicas a serem administradas junto com o auxiliar de enfermagem; outro auxilia o médico clínico geral durante uma consulta e realiza anotação em prontuário, realiza passagem de plantão, orientando tarefas a serem desenvolvidas no turno seguinte; um outro solicita coleta de sangue para o laboratório e elabora escala de auxiliares de enfermagem para atividades diárias a serem desenvolvidas pelos mesmos (banho, servir café, corte de unhas, arrumação de camas, entre outras).

As ações acima citadas,caracterizam a necessidade de tempo e continuidade do trabalho da enfermagem $^{(16)}$.

Ações burocráticas e administrativas- Essas foram as ações observadas que demandam grande parte do tempo dos profissionais investigados. A maioria elabora escalas de funcionários (plantão e férias); alguns realizam controle e fechamento do ponto do pessoal da equipe do setor pelo qual são responsáveis; outros participam de reuniões (de equipe, de gerentes e administrativas); outros também solicitam manutenção/conserto de materiais como cadeiras, mesas, chuveiros, vasos sanitários, entre outros serviços; ainda solicitam condução para transporte de pacientes/moradores para outros serviços de saúde ou passeios e/ou compras; um enfermeiro organiza o posto de enfermagem, repõe o material no armário (algodão, álcool, gazes, entre outros), elabora lista para compra de materiais de consumo, participa de sindicância interna do hospital, preenche papéis para autorização de saída de paciente do hospital (passeios e compras), arruma armários de pacientes sem ajuda dos mesmos e dá entrevista para a televisão sobre o trabalho realizado no setor pelo qual é responsável.
Notei que as ações burocráticas/administrativas são aquelas que demandam um tempo maior dos profissionais investigados, o que vem ao encontro de investigações anteriores que estudaram a prática de enfermagem psiquiátrica em várias instituições de assistência $^{(2,7,17-20)}$.

Nas observações e anotações realizadas, verifiquei que o que é esperado do enfermeiro é que ele cumpra os regulamentos, dê a medicação, ocupe-se da higiene dos pacientes, chame o médico quando necessário, e que a maioria dos enfermeiros assume esse papel cobrado.

No entanto, um dos enfermeiros investigados foge da regra geral. Questiona o perfil cobrado pelos outros, adota uma outra postura e, portanto, mostra-se insatisfeito com a conduta e papéis assumidos pelos colegas.

Durante sua formação, o enfermeiro foi direcionado para desenvolver ações técnicas claras e definidas. Quando está na área psiquiátrica, ser-Ihe-á exigida uma postura de iniciativa e criatividade, o que nem sempre lhe é oferecido na graduação e na instituição ${ }^{(21)}$.

Parece que o profissional, sem ter uma visão abrangente de suas atribuições, ocupa-se de tudo, como do livro de ocorrências, da roupa, do ponto (registro de entrada e saída de funcionários), do vaso sanitário entupido, dos pedidos de material, entre outras coisas. Porém, fica faltando o fundamental, ou seja, definir o plano terapêutico que deve ser desenvolvido pela enfermagem e a orientação dos auxiliares de enfermagem na interação com os pacientes.

Se o Hospital vislumbrar mudanças na assistência ao indivíduo em sofrimento deverá oferecer um bom preparo à enfermagem ${ }^{(22)}$.

O enfermeiro deverá ser preparado para atuar em novos modelos, com enfoque de serviços extra-hospitalares e de reabilitação psicossocial, e assumir novas tarefas, como, por exemplo, maior envolvimento com familiares, adequando-se às mudanças advindas da atual política de saúde mental vigente no país.

\section{CONSIDERAÇÕES FINAIS}

Os resultados obtidos possibilitaram-nos visão parcial da atual situação das ações de enfermagem em um hospital psiquiátrico estatal no interior do Estado de São Paulo, apontando para a predominância das ações de natureza burocrática e administrativa. 
Em reunião com os profissionais investigados para apresentar os resultados e discutirmos a necessidade de uma intervenção na assistência de enfermagem, foram salientados alguns pontos que consideraram importantes para serem discutidos, como: a necessidade do envolvimento da equipe no Programa Terapêutico Individual (PTI), atualmente em discussão na instituição; a necessidade de supervisão constante dessa equipe; a discussão do papel do enfermeiro dentro da atual proposta de política de saúde mental do país; a reflexão sobre o que leva os enfermeiros a centralizarem suas ações em burocrático/administrativa; a necessidade de repensar o papel do enfermeiro dentro do contexto da Instituição; a importância do relacionamento enfermeiros/pacientes e

\section{REFERÊNCIAS BIBLIOGRÁFICAS}

1. Souza MCBM. Estudo bibliográfico das produções de enfermagem psiquiátrica no Brasil, no período de 1932 a 1993. [dissertação]. Ribeirão Preto (SP): Escola de Enfermagem de Ribeirão Preto/USP; 1995.

2. Mello e Souza MCB. Enfermeiros assistenciais das instituições psiquiátricas de Ribeirão Preto: caracterização, formação e atuação. [tese]. Ribeirão Preto (SP): Escola de Enfermagem de Ribeirão Preto/USP; 1999.

3. Alencastre MB, organizadora. Estudo sobre o ensino de enfermagem psiquiátrica e saúde mental no Brasil. ljuí (RS): Unijuí; 2000.

4. Amarante P. Asilos, alienados e alienistas: uma pequena história da psiquiatria no Brasil. In: Amarante $\mathrm{P}$, organizador. Psiquiatria social e reforma psiquiátrica. Rio de Janeiro (RJ): Fiocruz; 1994.

5. Contel JO. Hospital psiquiátrico regional: considerações sobre sua origem, atualidade e futuro. Neurobiologia 1980 julho/setembro; 43(3):265-82.

6. Baldi VM. A atuação do enfermeiro psiquiátrico em um macro-hospital estatal: análise de uma experiência grupal. [dissertação]. Ribeirão Preto (SP): Escola de Enfermagem de Ribeirão Preto/USP; 1992.

7. Saeki T. Análise da prática do enfermeiro em um hospital psiquiátrico. [tese]. Ribeirão Preto (SP): Escola de Enfermagem de Ribeirão Preto/USP; 1994.

8. Decreto n 44.786 de 23 de março de 2000. Altera a denominação do Hospital Psiquiátrico de Ribeirão Preto, dispõe sobre sua reorganização e dá providências correlatas. Diário Oficial do Estado, 2000. 24 de março, seção I, p. 1-3. 9. Minayo MCS. O desafio do conhecimento: pesquisa qualitativa em saúde. 4를 ed. São Paulo (SP): Hucitec-Abrasco; 1996.

10. Lüdke M, André MEDA. Pesquisa em educação: abordagens qualitativas. São Paulo (SP): EPU; 1986.

11. Fernandes JD. O ensino de enfermagem psiquiátrica no Brasil. [dissertação]. Salvador (BA): Universidade Federal da Bahia; 1975. enfermeiros/funcionários; a instituição de um programa de educação continuada para os trabalhadores da Instituição.

Assim, os enfermeiros parecem reconhecer a necessidade de uma revisão do papel e conduta profissional, mas solicitaram um tempo maior para refletirem sobre o quadro apresentado e a possibilidade de intervenção na equipe de enfermagem para melhorar a qualidade de assistência.

Penso que estudos dessa natureza podem contribuir para a reflexão da prática dos enfermeiros psiquiátricos, com vistas à melhoria da assistência prestada ao indivíduo em sofrimento mental, a partir da compreensão de que se faz necessário repensar o papel do enfermeiro psiquiátrico.

12. Barros S. O louco, a loucura e a alienação institucional: o ensino de enfermagem psiquiátrica sub judice. [tese]. São Paulo. Escola de Enfermagem/USP; 1996.

13. Braga VAB. A enfermagem e a disciplina enfermagem psiquiátrica: visão da aluna. [dissertação]. Ribeirão Preto (SP): Escola de Enfermagem de Ribeirão Preto/USP; 1993.

14. Braga $\mathrm{VAB}$. O ensino de enfermagem psiquiátrica no Ceará e a reforma psiquiátrica: avanços e recuos. [tese]. Ribeirão Preto (SP): Escola de Enfermagem de Ribeirão Preto/ USP; 1998.

15. Kantorski LP. O ensino de enfermagem psiquiátrica e saúde mental e a reforma psiquiátrica no Rio Grande Sul. [tese]. Ribeirão Preto (SP): Escola de Enfermagem de Ribeirão Preto/USP; 1998.

16. Xavier IM,(coordenador). Subsídios para a construção da assistência de enfermagem rumo à reforma sanitária. Rev Bras Enfermagem 1987; 40(2/3):177-80.

17. Filizola CLA. O papel do enfermeiro psiquiátrico: oprimido e opressor. [dissertação]. São Paulo (SP): Escola de Enfermagem/USP; 1990.

18. Fraga MNO. A prática de enfermagem psiquiátrica: subordinação e resistência. [tese]. Ribeirão Preto (SP): Escola de Enfermagem de Ribeirão Preto/USP; 1992.

19. Colvero LA. O significado de ser enfermeiro em ambulatório de saúde mental. [dissertação]. São Paulo (SP): Escola de Enfermagem/USP; 1994.

20. Bertoncello NMF. O processo de trabalho em ambulatório de saúde mental: a prática da enfermeira. [tese]. Ribeirão Preto (SP): Escola de Enfermagem de Ribeirão Preto/USP; 1997.

21. Rocha RM. Enfermagem psiquiátrica: que papel é este? Rio de Janeiro (RJ): Instituto Franco Basaglia/Te Cora; 1994. 22. Cerqueira L. Psiquiatria social: problemas brasileiros de saúde mental. Rio de Janeiro (RJ): Atheneu; 1987. 